\title{
The status of emergency obstetric and newborn care in post-conflict eastern DRC: a facility-level cross-sectional study
}

Serge-André Mizerero ${ }^{1 *}$ (D, Calistus Wilunda ${ }^{2}$, Patou Masika Musumari ${ }^{3,4}$, Masako Ono-Kihara ${ }^{3}$, Gerrye Mubungu ${ }^{5}$, Masahiro Kihara ${ }^{3}$ and Takeo Nakayama'

\begin{abstract}
Background: Pregnancy-related mortality remains persistently higher in post-conflict areas. Part of the blame lies with continued disruption to vital care provision, especially emergency obstetric and newborn care (EmONC). In such settings, assessment of EmONC is essential for data-driven interventions needed to reduce preventable maternal and neonatal mortality. In the North Kivu Province (NKP), the epicentre of armed conflict in eastern Democratic Republic of the Congo (DRC) between 2006 and 2013, the post-conflict status of EmONC is unknown. We assessed the availability, use, and quality of EmONC in 3 health zones (HZs) of the NKP to contribute to informed policy and programming in improving maternal and newborn health (MNH) in the region.
\end{abstract}

Method: A cross-sectional survey of all 42 public facilities designated to provide EmONC in 3 purposively selected HZs in the NKP (Goma, Karisimbi, and Rutshuru) was conducted in 2017. Interviews, reviews of maternity ward records, and observations were used to assess the accessibility, use, and quality of EmONC against WHO standards.

Results: Only three referral facilities (two faith-based facilities in Goma and the MSF-supported referral hospital of Rutshuru) met the criteria for comprehensive EmONC. None of the health centres qualified as basic EmONC, nor could they offer EmONC services $24 \mathrm{~h}, 7$ days a week (24/7). The number of functioning EmONC per 500,000 population was 1.5. Assisted vaginal delivery was the least performed signal function, followed by parenteral administration of anticonvulsants, mainly due to policy restrictions and lack of demand. The $3 \mathrm{HZs}$ fell short of WHO standards for the use and quality of EmONC. The met need for EmONC was very low and the direct obstetric case fatality rate exceeded the maximum acceptable level. However, the proportion the proportion of births by caesarean section in EmONC facilities was within acceptable range in the HZs of Goma and Rutshuru. Overall, the intrapartum and very early neonatal death rate was $1.5 \%$.

Conclusion: This study provides grounds for the development of coordinated and evidence-based programming, involving local and external stakeholders, as part of the post-conflict effort to address maternal and neonatal morbidity and mortality in the NKP. Particular attention to basic EmONC is required, focusing on strengthening human resources, equipment, supply chains, and referral capacity, on the one hand, and on tackling residual insecurity that might hinder 24/7 staff availability, on the other.

\footnotetext{
* Correspondence: sergemizerero@gmail.com

${ }^{1}$ Graduate School of Medicine, School of Public Health, Department of

Health Informatics, Kyoto University, Kyoto, Japan

Full list of author information is available at the end of the article
}

(C) The Author(s). 2021 Open Access This article is licensed under a Creative Commons Attribution 4.0 International License, which permits use, sharing, adaptation, distribution and reproduction in any medium or format, as long as you give appropriate credit to the original author(s) and the source, provide a link to the Creative Commons licence, and indicate if changes were made. The images or other third party material in this article are included in the article's Creative Commons licence, unless indicated otherwise in a credit line to the material. If material is not included in the article's Creative Commons licence and your intended use is not permitted by statutory regulation or exceeds the permitted use, you will need to obtain permission directly from the copyright holder. To view a copy of this licence, visit http://creativecommons.org/licenses/by/4.0/ The Creative Commons Public Domain Dedication waiver (http://creativecommons.org/publicdomain/zero/1.0/) applies to the data made available in this article, unless otherwise stated in a credit line to the data. 
Keywords: Emergency obstetric and newborn care, Post conflict, Eastern Democratic Republic of the Congo, NorthKivu province, Process indicators, Maternal and newborn care

\section{Background}

Emergency obstetric and newborn care (EmONC) is globally recognized as an essential health package for reducing preventable maternal and neonatal mortality, particularly in countries with persistently higher mortality rates [1-5]. Most of these countries are located in sub-Saharan Africa (SSA) [6, 7], a region that has witnessed the majority of armed conflicts over the past 3 decades [8]. Research shows that conflict disproportionately affects maternal and child health, both during and years after it has ended [9-15], and that many of the countries where most maternal and child deaths occur are experiencing or have emerged from conflict $[16,17]$. Some have argued that reduced availability/low quality of EmONC services is 'the single most important factor implicated in maternal deaths in conflict and postconflict settings'(12). Accordingly, it is of vital importance to improve access to quality EmONC in conflictaffected settings through data-driven programming.

The EmONC life-saving services, or signal functions, define 2 types of complementary health facilities based on their capacity to provide, within a 3-month period, the 7 basic signal functions or all 9 signal functions when pregnancy- and childbirth-related complications occur (see Table 1). These complications, including haemorrhage, hypertensive disorders, sepsis, obstructed labour, complications of abortion, and intrapartum related asphyxia, cause most maternal deaths, stillbirths, and early neonatal deaths [18-20]. Their occurrence is often unpreventable [21], unforeseeable [1], and expected in about $15 \%$ of women during pregnancy, childbirth, and the immediate postpartum [22]. The disruptive and lingering effects of conflict on health services provision-deficient health personnel, damaged health infrastructure, inadequate healthcare coordination, and weak supply chains-contribute to increased vulnerability to adverse outcomes related to these complications [15, 23].

The Inter-Agency Working Group for Reproductive Health in Crises (IAWG) guidelines place a priority on ensuring optimal provision of EmONC services during post-conflict recovery to address excess mortality in mothers and newborns [24]. A clear understanding of the capacity of the existing health system to respond to the reproductive health needs of affected populations is essential for effective program planning and implementation, especially with regard to safe motherhood [25]. For example, the IAWG advocates the use of a wellestablished Needs Assessment Toolkit [26] that allows for a system of EmONC process/performance evaluation against United Nations (UN) standards, which is instrumental in identifying gaps and guiding programmes.

From 2006 to 2013, state-based conflict (i.e., armed fighting between a state and an opposition group resulting in at least 25 battle-related deaths in a year) disproportionately affected the eastern Democratic Republic of the Congo (DRC) in general and the North Kivu Province (NKP) in particular [27]. During that period, the North Kivu Province witnessed 98 of the 128 conflict events that occurred across the country, opposing government troops against foreign-backed rebel groups [27]. As a reflection of the impact of conflict on public health, the east of DRC recorded higher preventable mortality, including excess neonatal mortality, than in the west $[28,29]$. In the North Kivu Province, maternal mortality was as high as 790 deaths per 100,000 live births for the first half of 2013 [30]. Recent evidence indicates that proximity to and deadliness and duration of armed conflict in SSA are associated with indirect effects on the survival of mothers and their babies; these effects persist for years after the conflict has ceased [15, 31]. This underscores the need for sustained and informed measures

Table 1 Signal functions for basic and comprehensive EmONC health facilities

\begin{tabular}{ll}
\hline Basic EmONC & Comprehensive EmONC \\
\hline \#1. Administration of parenteral antibiotics & Performs \#1 through \#7, plus \\
\#2. Administration of uterotonic drugs & \#8. Surgery (Caesarean section) \\
\#3. Administration of anticonvulsants & \#9. Blood transfusion \\
\#4. Manual removal of placenta (MRP) & \\
\#5. Removal of retained products of conception (RRP) & \\
\#6. Assisted vaginal delivery (AVD) & \\
\#7. Neonatal resuscitation with bag and mask &
\end{tabular}


in revitalizing essential health services, including EmONC

However, in the North Kivu Province, there is a lack of data on the post-conflict status of EmONC. This situation can be explained in part by poor government stewardship and 'the proliferation of fragmented humanitarian and recovery initiatives', factors previously observed in other post-conflict contexts in SSA (South Sudan and Sierra Leone) and eastern DRC [32-35]. These often lead to uncoordinated health interventions, with little attention to data-driven plans and policies that are customized to local contexts [36, 37]. Therefore, this study aimed to contribute to filling this gap by assessing the availability, use and quality of EmONC in 3 Health Zones (HZs) in the North Kivu Province of eastern DRC. Evidence generated from this study will contribute to informed programming and data-driven interventions, involving local and external stakeholders, as part of the post-conflict effort to improve maternal and neonatal health in the Province.

\section{Methods}

\section{Study design and setting}

This is a cross-sectional survey at health facility level conducted from March to May 2017 in the North Kivu Province (NKP). From 2006 to 2013, this Province accounted for about two thirds of battle-related deaths across the country, reflecting the intensity of conflict events between government troops and two major rebel groups backed by neighbouring countries (the Congrès National pour la Défense du Peuple [CNDP] and the Mouvement du 23 Mars [M23]) [27]. The NKP counts 34 health zones (HZ) out of the 515 nationwide, serving urban, rural or urbano-rural administrative areas with at least 100,000 inhabitants and a maximum diameter of $150 \mathrm{~km} \mathrm{[38].}$

The HZ is a decentralized entity that constitutes the operational unit for planning and implementing health services in DRC. It operates as a tiered system consisting of a network of health facilities, supervised by the Central Bureau of the Health Zone (CBHZ), with increasing service capacity along a chain of referral [38]. Health centres $(\mathrm{HC})$ are first-line facilities dedicated to primary health care tasks (including the provision of antenatal care and the management of normal deliveries), delegated to a team of versatile nurses. They refer cases that are beyond their means and competencies to a referral health centre (RHC) or the referral hospital (RH).

Three health zones (HZs), namely Goma, Karisimbi, and Rutshuru, were purposively selected based on their 'red flag' proximity-that is, within a $50 \mathrm{~km}$ range $[15$, 31 , to most of the deadliest conflict events from 2006 to 2013 [27, 39], and based on their position across the urban/rural spectrum in the North-Kivu Province to represent the status of maternal and neonatal health care in urban (Goma), urbano-rural (Karisimbi) and rural (Rutshuru) post-conflict settings.

The HZs of Goma and Karisimbi integrate both stateowned and private not-for-profit (religious or other) referral facilities (RHs and RHCs) into the public health sector. Not-for-profit organizations (NFPO) have entered into a contractual agreement with the state specifying the rights and duties of both partners; however, they remain largely autonomous in terms of management.

\section{Selection of health facilities and sample size}

We selected only public health facilities (state-owned and private not-for-profit) providing maternal and neonatal health $(\mathrm{MNH})$ care across the $3 \mathrm{HZs}$. The rationale for this was that institutional births represent $92 \%$ of deliveries in North Kivu province, of which $80 \%$ take place in public facilities [40]. A complete list of facilities with maternal services, including $\mathrm{HCs}$, RHCs, and RHs, was provided by the respective CBHZs. Therefore, all 42 public facilities providing $\mathrm{MNH}$ services in the $3 \mathrm{HZs}$ were included in the study. Table 2 shows these health facilities per $\mathrm{HZ}$ and per level. As per the DRC Ministry of Health $(\mathrm{MOH})$ guidelines, all $\mathrm{HCs}$ and referral facilities (RHs and RHCs) are required to provide basic and comprehensive EmONC $24 \mathrm{~h}$ a day and 7 days a week, respectively.

\section{Data collection}

Data were obtained from medical records and registries for the year 2016, as well as from interviews with relevant in-charges and observation of available equipment and medical supplies, using the EmONC Needs Assessment (NA) toolkit. This toolkit is organised in modules of questionnaires developed and refined over time by the Averting Maternal Death and Disability (AMDD) programme at Columbia University Mailman School of Public Health. The WHO, UNFPA, and UNICEF have adopted these modules to capture key indicators of availability, use, and quality of EmONC services. These indicators are constructed to inform interventions aiming to reduce maternal and neonatal mortality by identifying gaps, monitoring implementation, and measuring progress [26]. Moreover, these modules have been proven useful in conflict-affected settings [41].

Prior to the survey, we held meetings with the Chief Medical Officer (CMO) and the CBHZ team of each HZ. During these meetings, the French versions of the AMDD NA modules were discussed and adapted to suit the local context, guided by the research objectives. Adaptations included editing/deleting some questions and response options. The CMOs granted authorizations to collect data at the surveyed facilities and provided 
Table 2 Public health facilities providing maternal and neonatal care per level and per study Health Zones (HZ) in the North-Kivu province of Eastern Democratic Republic of the Congo, 2017

\begin{tabular}{|c|c|c|c|c|c|}
\hline $\begin{array}{l}\text { Health Zone } \\
\text { (HZ) }\end{array}$ & Population & $\begin{array}{l}\text { Expected number of live } \\
\text { births* }\end{array}$ & Referral hospitals (RH) & $\begin{array}{l}\text { Referral health centres } \\
\text { (RHC) }\end{array}$ & $\begin{array}{l}\text { Health centres } \\
\text { (HC) }\end{array}$ \\
\hline Goma & 243,685 & 9869 & $\begin{array}{l}\text { Hôpital Provincial du Nord-Kivu } \\
\text { Hôpital Général Charité } \\
\text { Maternelle }^{\dagger}\end{array}$ & $\begin{array}{l}\text { CSR Carmel }^{+} \\
\text {CSR Heal Africa } \\
\text { CSR Keshero }^{+} \\
\text {CH Bethesda }\end{array}$ & $\begin{array}{l}\text { CS Mapendo } \\
\text { CS Buhimba } \\
\text { CS Casop } \\
\text { CS Afia Himbi } \\
\text { CS Kasika }\end{array}$ \\
\hline Karisimbi & 461,089 & 21,164 & $\begin{array}{l}\text { Hôpital Général Virunga } \\
\text { Hôpital Militaire Régional }\end{array}$ & $\begin{array}{l}\text { CSR Kahembe } \\
\text { CSR Albert Barthel } \\
\text { CH Notre dame d'Afrique } \\
\text { CH La Résurrection }\end{array}$ & $\begin{array}{l}\text { CS Murara } \\
\text { CS Bujovu } \\
\text { CS Majengo } \\
\text { CS Lubango } \\
\text { CS La solidarité } \\
\text { CS Virunga } \\
\text { CS Mabanga } \\
\text { CS Katoyi }\end{array}$ \\
\hline Rutshuru & 283,432 & 13,009 & Hôpital Général de Rutshuru ${ }^{\ddagger}$ & $\begin{array}{l}\text { CSR Kinyandonyi } \\
\text { CSR Kiwanja } \\
\text { CSR Mapendo } \\
\text { CSR Rubare } \\
\text { CSR Vitshumbi }\end{array}$ & $\begin{array}{l}\text { CS Rutshuru } \\
\text { CS Biruma } \\
\text { CS Buturande } \\
\text { CS Kalengera } \\
\text { CS Kakomero } \\
\text { CS Katale } \\
\text { CS Kibututu } \\
\text { CS Mabungo } \\
\text { CS Murambi } \\
\text { CS Rugari } \\
\text { CS Umoja }\end{array}$ \\
\hline Total & 988,206 & 44,042 & 5 & 13 & 24 \\
\hline
\end{tabular}

Source: Central bureau of the Health Zones (CBHZ)

${ }^{*}$ calculated as population $x$ crude birth rates (CBR, as reported in the 2013-2014 DRC Demographic Health Survey [42])

CSR: centre de santé de référence, $\mathrm{CH}$ : centre hospitalier, $\mathrm{CS}$ : centre de santé

${ }^{\dagger}$ Non-for-profit organisations including 5 faith-based and 1 NGO owned (CSR Heal Africa) health facilities

₹ Public RH supported by Médecin Sans Frontières

relevant information on public health facilities (population covered, ownership/management).

Four research assistants, all final year students at the Midwifery Section of the Institut Supérieur des Technique Médicales de Goma, were recruited. They received 3-day training to ensure a clear understanding of the objectives/methods of the survey, the content of the modules and how to fill them out. Didactic sessions covered proper interviewer behaviour, relevant ethical considerations, and appropriate identification of direct obstetric complications (ante- and post-partum haemorrhage, severe pre-eclampsia/eclampsia, obstructed labour, ectopic pregnancy, and postpartum sepsis) using the WHO definitions [26].

In each HZ, the Principal Investigator (PI) organized a data collection schedule in consultation with the heads of health facilities. The PI supervised data collection, which followed a top-down order in every HZ (i.e., RHs first, then RHCs and HCs). Data on deliveries, pregnancy-related and childbirth complications, maternal, foetal and early neonatal outcomes, and procedures related to EmONC were extracted from facility registries, procedure reports, and from patient records when necessary. Interviews were conducted with heads of facilities (medical doctors in referral facilities and registered nurses in $\mathrm{HCs}$ ) and in-charges of units of interest (maternity ward, delivery room, operation theatre, pharmacy, and laboratory), or with a direct collaborator. They focused on the provision of signal functions during the last 3 months, the number and composition of health staff, and the availability of equipment and medical supplies. Facility walk-throughs were carried out to observe the availability of medical supplies, facilities, and equipment.

\section{Data management and analysis}

During data collection, a number was attributed to each facility and written at the top of every page of each module, starting with RH, then RHC and HC, in Goma, Karisimbi, and Rutshuru, respectively. EpiData 3.1 was used to create data entry fields with in-build checks and each module had its own file. Data were double entered by 2 trained data entry operators and discordances were sorted out by revisiting the respective questionnaires.

Data keyed in using EpiData were exported to Stata 15 for data handling and analysis. Descriptive statistics including means and medians for continuous variables, and frequencies and proportions for categorical variables were performed as appropriate. Analyses were guided by the Handbook on Monitoring Emergency Obstetric Care 
by UN partners and the AMDD programme to assess the performance of signal functions and calculate indicators of availability, use, and quality of EmONC services in these health zones. Estimates of the expected live births were used to compute EmONC indicators.

\section{Ethical considerations}

This study was approved by Kyoto University Graduate School and Faculty of Medicine, Ethics Committee, as well as by the Ethics Committee of the University of Kinshasa School of Public Health.

\section{Results}

\section{Profile of surveyed health facilities and volume of} deliveries

Of the 42 public health facilities surveyed in the $3 \mathrm{HZs}$, 24 were health centres, all owned and managed by the state, and 18 were referral institutions, of which 5 were RHs and 13 were RHCs (Table 2). In the HZ of Goma, most referral facilities $(5 / 6$; 83\%) were owned and managed by private non-for-profit organizations (NFPO) including $1 \mathrm{RH}$ by the Catholic church, 3 RHCs by Protestant churches, and 1 RHC by a non-governmental organisation. In the $\mathrm{HZ}$ of Karisimbi, half of the referral facilities (3 RHCs) were faith-based organisations managed by Protestant churches. All referral facilities in the $\mathrm{HZ}$ of Rutshuru were state owned. However, as part of the humanitarian response to conflict-related health crises, the RH in the HZ of Rutshuru was assisted and comanaged by Médecins Sans Frontières (MSF), dating back to 2005. MSF built a maternity-waiting home near the $\mathrm{RH}$ and, among other things, offered full exemption from user fees for all CS and charged a flat-fee of USD 5 for vaginal deliveries.

In 2016, the surveyed facilities conducted 35,283 deliveries: 7824 in Goma, 14.997 in Karisimbi, and 12,467 in Rutshuru. Of note, not-for-profit referral facilities (RHs and RHCs) attended $45.8 \%(10,459 / 22,821)$ of deliveries and $73.2 \%(2446 / 3337)$ of CS in the HZs of Goma and Karisimbi, while $36.7 \%(4578 / 12,462)$ of deliveries and $83 \%$ of CS (1491/1797) in the HZ of Rutshuru took place at the $\mathrm{RH}$.

\section{Provision of signal functions}

Only $17 \%$ (3/18) of the referral facilities (the faith-based $\mathrm{RH}$ and 1 faith-based RHC in Goma, and the RH in Rutshuru) provided the nine signal functions within the last 3 months prior to the survey and thus met the criteria for functioning cEmONC facilities (see Table 3). All the remaining $(83 \%$; $15 / 18)$ were partial $c E m O N C$ facilities (i.e., 8 or fewer signal functions provided). Of these, $20 \%$ $(3 / 15)$ were short of a signal function (AVD) to qualified as functioning cEmONC facilities, which included 1 faith-based RHC and the government RH in Goma, and 1 faith-based RHC in Karisimbi.

Among the surveyed health centres (HCs), none performed all the $7 \mathrm{bEmONC}$ signal functions during the last three months, nor could they offer EmONC services 24 h, 7 days a week (24/7). Most HCs in Rutshuru (91\%, $10 / 11)$ and Karisimbi $(88 \% ; 7 / 8)$ performed only 1 to 3 signal functions of bEmONC, whereas in Goma, 80\% (4/ 5) of HCs performed 4 to 6 basic signal functions, of which two could have qualified as functioning bEmONC facilities had they performed AVD.

Assisted vaginal delivery (AVD) was the least performed signal function $(7.1 \% ; 3 / 42)$, followed by parental administration of anticonvulsants $(33.3 \% ; 14 / 42)$ and neonatal resuscitation $(45.2 \% ; 19 / 42)$ (Table 3$)$. 'Policy issue' (i.e., HZ or facility policies not allowing the performance of a signal function) was the reason reported by about three-quarters $(74.3 \% ; 29 / 39)$ of facilities that did not perform AVD, including all HCs in Rutshuru, $87.5 \%(7 / 8)$ of HCs in Karisimbi, and 60\% (3/5) of HCs in Goma. Similarly, 'no indication' (i.e., no patient needing a signal function came to the facility) was the reason given by $71.4 \%(20 / 28)$ and $69.5 \%(16 / 23)$ of facilities that did not perform parenteral administration of anticonvulsants and neonatal resuscitation, respectively. Most of the facilities that did not indicate parenteral anticonvulsants $(75 \% ; 15 / 20)$ and neonatal resuscitation $(81.3 \% ; 13 / 16)$ were HCs.

Further analyses showed that nearly all the facilities that reported 'no indication' for parenteral administration of anticonvulsants $(95.0 \% ; 19 / 20)$ didn't provide this signal function even during the past 12 months. Also, $62.5 \%(10 / 16)$ and $50.0 \%(4 / 8)$ of facilities that didn't provide neonatal resuscitation (NR) and AVD due to no indication, respectively, didn't have the necessary equipment to perform these signal functions (i.e., neonatal bag and mask for NR and vacuum extractor or forceps for AVD).

\section{Indicators of EmONC}

The existing public health facilities designated to provide EmONC services exceeded the minimum number of EmONC delivery points needed per 500,000 population in the $3 \mathrm{HZs}$ (Table 4). However, none of the health zones achieved the minimum number of functioning EmONC facilities as per the WHO recommendations (at least $5 \mathrm{EmONC}$ facilities for every 500,000 population with at least $1 \mathrm{cEmONC}$ facility), with an unmet need less pronounced in the $\mathrm{HZ}$ of Goma (Tables 4 and 5). In other words, the number of functioning EmONC facilities per 500,000 population in the study HZs was 1.5 .

Overall, $14.3 \%(6331 / 44,042)$ of expected births in 2016 occurred in functioning EmONC facilities (Table 5). In the HZ of Rutshuru, this proportion (35.2\%; 4578/13, 
Table 3 Signal functions performed by designated EmONC facilities per level in the 3 health zones (HZs) in the North-Kivu Province of Eastern Democratic Republic of the Congo (DRC), 2017

\begin{tabular}{|c|c|c|c|c|c|c|c|c|c|c|c|}
\hline Health zones & $\begin{array}{l}\text { \#1. } \\
\text { Antibiotics }\end{array}$ & $\begin{array}{l}\# 2 . \\
\text { Oxytocics }\end{array}$ & $\begin{array}{l}\text { \#3. Anti- } \\
\text { convulsants }\end{array}$ & $\begin{array}{l}\text { \#4. } \\
\text { MRP }\end{array}$ & $\begin{array}{l}\text { \#5. } \\
\text { RRP }\end{array}$ & $\begin{array}{l}\# 6 . \\
\text { AVD }\end{array}$ & $\begin{array}{l}\text { \#7. Neonatal } \\
\text { resuscitation }\end{array}$ & $\begin{array}{l}\text { \#8. } \\
\text { Caesarean } \\
\text { section }\end{array}$ & $\begin{array}{l}\text { \#9. Blood } \\
\text { transfusion }\end{array}$ & $\begin{array}{l}\text { Facilities } \\
\text { performing } \\
\text { all signal } \\
\text { function* }\end{array}$ & $\begin{array}{l}\text { Facilities } \\
\text { providing } \\
\text { services } 24 \mathrm{~h} \\
\text { a day and } 7 \\
\text { days a week }\end{array}$ \\
\hline & $n(\%)$ & $\mathrm{n}(\%)$ & $n(\%)$ & $n(\%)$ & $n(\%)$ & $\mathrm{n}(\%)$ & $n(\%)$ & $n(\%)$ & $n(\%)$ & $\mathrm{n}(\%)$ & $\mathrm{n}(\%)$ \\
\hline \multicolumn{12}{|l|}{ Goma } \\
\hline $\begin{array}{l}\mathrm{RH} \text { and } \mathrm{RHC} \\
(n=6)\end{array}$ & $6(100)$ & $6(100)$ & $6(100)$ & $6(100)$ & $6(100)$ & $2(33.3)$ & $6(100)$ & $6(100)$ & $5(83.3)$ & $2(33.3)$ & $6(100)$ \\
\hline $\mathrm{HC}(n=5)$ & $5(100)$ & $5(100)$ & $3(60.0)$ & $5(100)$ & $4(80.0)$ & $0(0)$ & $3(60.0)$ & NA & NA & $0(0)$ & $0(0)$ \\
\hline \multicolumn{12}{|l|}{ Karisimbi } \\
\hline $\begin{array}{l}\mathrm{RH} \text { and } \mathrm{RHC} \\
(\mathrm{n}=6)\end{array}$ & $6(100)$ & $6(100)$ & $3(50.0)$ & $6(100)$ & $6(100)$ & $0(0)$ & $6(100)$ & $6(100)$ & $4(66.7)$ & $0(0)$ & $6(100)$ \\
\hline $\mathrm{HC}(n=8)$ & $5(62.5)$ & $8(100)$ & $0(0)$ & $8(100)$ & $2(25.0)$ & $0(0)$ & $1(12.5)$ & NA & NA & $0(0)$ & $0(0)$ \\
\hline \multicolumn{12}{|l|}{ Rutshuru } \\
\hline $\begin{array}{l}\mathrm{RH} \text { and } \mathrm{RHC} \\
(\mathrm{n}=6)\end{array}$ & $4(66.7)$ & $6(100)$ & $2(33.3)$ & $5(83.3)$ & $5(83.3)$ & $1(16.7)$ & $2(33.3)$ & $4(66.7)$ & $1(16.7)$ & $1(16.7)$ & $4(66.7)$ \\
\hline$H C(n=11)$ & 7 (63.6) & $11(100)$ & $0(0)$ & $11(100)$ & $1(9.1)$ & $0(0)$ & $1(9.1)$ & NA & NA & $0(0)$ & $0(0)$ \\
\hline \multicolumn{12}{|l|}{ All HZs } \\
\hline $\begin{array}{l}\mathrm{RH} \text { and } \mathrm{RHC} \\
(n=18)\end{array}$ & 16 (88.9) & $18(100)$ & $11(61.1)$ & $17(94.4)$ & 17 (94.4) & $3(16.7)$ & $14(77.8)$ & $16(88.9)$ & $10(56)$ & $3(16.7)$ & 16 (88.9) \\
\hline$H C(n=24)$ & 17 (70.8) & $24(100)$ & $3(12.5)$ & $24(100)$ & 7 (29.2) & $0(0)$ & $5(20.8)$ & NA & NA & $0(0)$ & $0(0)$ \\
\hline Total $(n=42)$ & 33 (78.6) & $42(100)$ & $14(33.3)$ & $41(97.6)$ & $24(57.1)$ & $3(7.1)$ & 19 (45.2) & 16 (88.9†) & $10(55.6+)$ & $3(7.1)$ & $16(38.1)$ \\
\hline
\end{tabular}

MRP: manual removal of placenta, RRP: removal of retained placenta, AVD: assisted vaginal delivery

$\mathrm{HC}$ : health centres, RHC: referral health centre, $\mathrm{RH}$ : referral hospital

* \#1-\#7 for HC and \#1-\#9 for R and RHC

tCalculated with the total number $(n=18)$ of $\mathrm{RH}$ and $\mathrm{RHC}$ as the denominator

NA: not applicable

009) was about twice as high as in the HZ of Goma $(17.8 \% ; 1753 / 9869)$. Deliveries in surveyed facilities in the $3 \mathrm{HZs}$ (i.e., institutional deliveries) represented $80.1 \%(35,283 / 44,042)$ of births in 2016. In Goma, Karisimbi, and Rutshuru, the institutional delivery rate was $79.3 \%$ (7824/9869), $70.9 \%(14,997 / 21,164)$, and $95.8 \%$ $(12,462 / 13,009)$, respectively (Table 5$)$.

The proportion of MDOC managed in functioning EmONC facilities was only $3.1 \%(202 / 6606)$ overall (Table 5). This proportion was 6.6\% (97/1480) in the HZ of Goma and 5.4\% (105/195) in the HZ Rutshuru. In contrast, the proportion of births by caesarean sections that took place in functioning EmONC facilities was $5.0 \%(2206 / 44,042)$ overall; $7.2 \%(715 / 9869)$ in the HZ of Goma and $11.5 \%(1491 / 13,009)$ in the HZ of Rutshuru. Caesarean deliveries in all referral facilities surveyed (i.e., population-based caesarean section rate [PCSR]) represented 11.7\% (5134/44,042) of expected births. In Goma, Karisimbi, and Rutshuru, the PCSR was 22.9\% (2261/ 9869), 5.1\% (1076/21,164), and $13.8 \%(1797 / 13,009)$, respectively (Table 5$)$.

With regards to the quality of EmONC, the direct obstetric case fatality rate (DOCFR) and the intrapartum and very early neonatal death rate (INDR) in EmONC facilities were $4.5 \%(9 / 202)$ and $1.9 \%$ (119/6331), respectively (Table 5). The DOCFR in Goma was higher $(5.2 \% ; 5 / 97)$ than that in Rutshuru $(3.8 \% ; 4 / 105)$ and the INDR $(1.2 \% ; 21 / 1753)$ about half of that in Rutshuru $(2.0 \% ; 95 / 4578)$. When including all facilities surveyed, the INDR was $1.5 \%(532 / 35,283)$, with very little variation between the HZs, and the DOCFR was 5.1\% (28/ 545). The highest DOCFR was in Karismbi (7.4\%; 9/ 121). Of note, all direct obstetric deaths occurred in referral facilities. Major direct obstetric complications (MDOC) by causes and related maternal deaths in the study HZs are shown in Table 6.

\section{Staff, supplies and equipment for EmONC}

Table 7 shows the staff available for EmONC in the surveyed facilities per $\mathrm{HZ}$ and per level of facilities. Overall, nurses represented the largest category of staff $(62.6 \%$; $325 / 519)$, followed by physicians $(25.0 \% ; 130 / 519)$ and midwives $(12.3 ; 64 / 519)$. In line with the $\mathrm{MOH}$ guidelines, HCs were staffed only with non-physician practitioners (nurses or midwives). All HCs had at least 2 nurses, the minimum number set in national guidelines, with only a third of them $(33.3 \%, 8 / 24)$ having midwives on staff.

Referral facilities employed a mix of cadres, including physicians (general practitioners and/or specialists), 
Table 4 Distribution of designated EmONC facilities in the study health zones (HZs) in the North-Kivu Province of eastern Democratic Republic of the Congo (DRC) in comparison with the minimum number of functioning EmONC facilities required by the World Health Organization (WHO), 2017

\begin{tabular}{|c|c|c|c|c|c|c|c|c|c|}
\hline \multirow{2}{*}{$\begin{array}{l}\text { Health } \\
\text { zones }\end{array}$} & \multirow{2}{*}{$\begin{array}{l}\text { Total } \\
\text { population }\end{array}$} & \multirow{2}{*}{$\begin{array}{l}\text { Minimum number } \\
\text { of EmONC } \\
\text { facilities for } 500 \text {, } \\
000 \text { population as } \\
\text { per the } \mathrm{WHO}^{\dagger}[\mathrm{a}]\end{array}$} & \multirow{2}{*}{$\begin{array}{l}\text { Number of } \\
\text { designated } \\
\text { cEmONC facilities } \\
\text { per } 500,000 \\
\text { population in the } \\
\text { study } \mathrm{HZs}^{\ddagger}\end{array}$} & \multirow{2}{*}{$\begin{array}{l}\text { Number of } \\
\text { designated } \\
\text { bEmONC facilities } \\
\text { per } 500,000 \\
\text { population in the } \\
\text { study } \mathrm{HZs}^{\ddagger}\end{array}$} & \multicolumn{2}{|c|}{ cEmONC facilities } & \multicolumn{2}{|c|}{ bEmONC facilities } & \multirow{2}{*}{$\begin{array}{l}\text { Functioning } \\
\text { EmONC } \\
\text { facilities as a } \\
\text { proportion of } \\
\text { the minimum } \\
\text { number } \\
\text { recommended } \\
\text { by the WHO } \\
([b+c] / a, \%)\end{array}$} \\
\hline & & & & & $\begin{array}{l}\text { Minimum } \\
\text { number } \\
\text { acceptable } \\
\text { by the } \\
\text { WHO }\end{array}$ & $\begin{array}{l}\text { Number of } \\
\text { functioning } \\
\text { cEmONC } \\
\text { facilities in } \\
\text { the study } \\
\text { HZs [b] }\end{array}$ & $\begin{array}{l}\text { Minimum } \\
\text { number } \\
\text { acceptable } \\
\text { by the } \\
\text { WHO }\end{array}$ & $\begin{array}{l}\text { Number of } \\
\text { functioning } \\
\text { bEmONC } \\
\text { facilities in } \\
\text { the study } \\
\text { HZs [c] }\end{array}$ & \\
\hline Goma & 243,685 & 3 & 12 & 10 & 1 & 2 & 2 & 0 & 66.7 \\
\hline Karisimbi & 461,089 & 5 & 7 & 9 & 1 & 0 & 4 & 0 & 0.0 \\
\hline Rutshuru & 283,432 & 3 & 11 & 19 & 1 & 1 & 2 & 0 & 33.3 \\
\hline All HZs & 988,206 & 10 & 9 & 12 & 2 & 3 & 8 & 0 & 30.0 \\
\hline
\end{tabular}

cEmONC: comprehensive emergency obstetric and newborn care, bEmONC: basic emergency obstetric and newborn care

tCalculated as population $/ 500,000 \times 5$ (rounded up)

$\neq$ Calculated as 500,000/population $\times$ number of designated EmONC or bEmONC facilities

nurses, and midwives. Nearly all $(94.1 \% ; 16 / 17)$ of the specialists (obstetricians and paediatricians) and over half $(54.0 \% ; 61 / 113)$ of the general practitioners worked in Goma. Most of the midwives $(82.8 \% ; 24 / 29)$ and specialists $(75.0 \% ; 12 / 16)$ in the HZs of Goma and Karisimbi were NFPO health workers. In the HZ of Rutshuru, $58.3 \%(14 / 24)$ of physicians were working at the referral hospital.

On average, there were fewer nurses on staff in the HCs located in the HZ of Rutshuru (median = 4, IQR 45) than in those located the HZs of Goma (median $=7$, IQR 6-7) and Karisimbi (median = 7.5, IQR 6.5-9). The median number of medical doctors in referral facilities was higher in the HZ of Goma (9.5, IQR 8-13) than in the HZs of Karisimbi (3, IQR 2-8) and Rutshuru (2, IQR $2-3)$.

Regarding the availability of essential drugs, equipment in the facilities surveyed, magnesium sulphate was the least available drug in the facilities surveyed $(45.2 \% ; 19 /$ 42). Vacuum extractors were the least available equipment $(21.4 \% ; 9 / 42)$, followed by filled oxygen cylinders and neonatal intravenous fluid sets (Table 8). These drugs and equipment were more frequently unavailable in HCs located in the HZs of Karisimbi and Rutshuru. There was a pattern whereby essential drugs and equipment for EmONC were more likely to be available in facilities located in the $\mathrm{HZ}$ of Goma. In the $\mathrm{HZ}$ of Rutshuru, 33\% (2/6) of the referral facilities, and 36\% (4/ 11) of the HCs did not have an operational laboratory because of a lack of equipment or technicians.

\section{Transport and communication means for referral}

The ten facilities with a functional ambulance (car or motorcycle) on-site were all referral facilities, including two thirds of referral facilities in Rutshuru (4/6) and half of the referral facilities both in Goma and Karismbi (Tale 7). They were all charging fees for the use of the ambulance when an institutional referral was requested, except for the referral hospital of Rutshuru where MSF took care of the ambulance operations. Relatedly, all the referral facilities in Goma and Karisimbi and 50\% (3/6) of those in Rutshuru had a means of communication (cell phone or two-way radio) for referral purposes, in stark contrast with almost none of the HCs $(4.1 \%, 1 / 24)$.

\section{Discussion}

According to the World Health Organization, the delivery of all EmONC services over the past 3 months by at least 5 facilities serving 500,000 inhabitants indicates that pregnancy-related complications are managed by trained personnel, medical equipment and supplies are sufficient, and skills are maintained [26]. Our findings show that only $30 \%$ of the minimum acceptable number EmONC facilities was met, with an availability gap less marked in the HZ of Goma than in the HZs of Rutshuru and Karisimbi, respectively. Relatedly, the process indicators related to the use and quality EmONC indicate that study HZs fell short of the WHO standards, except for the proportion of births by caesarean section. Resources needed for EmONC and institutional referral were scarce in surveyed HCs.

None of the surveyed HCs could offer EmONC 24h a day and 7 days a week (24/7). It is conceivable that this finding is related to the impact of residual insecurity that characterize post-conflict settings [42]. This situation impedes patients' admission or referral within the health system and tend to limit the availability of skilled health personnel to provide EmONC 24/7, especially in primary healthcare facilities, as suggested in previous studies in post-conflict SSA [43-45]. A high priority needs to be 


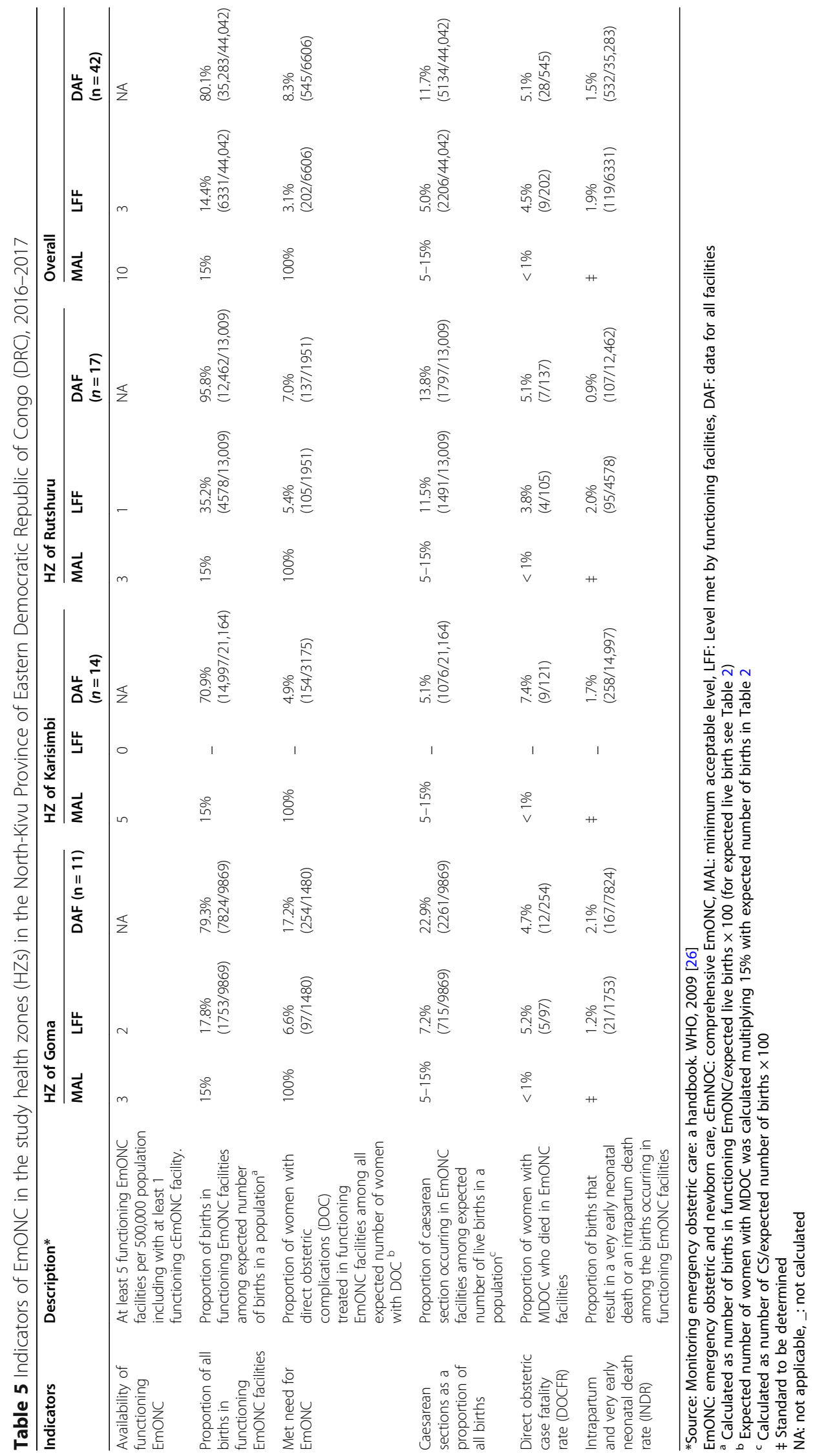


Table 6 Causes of Major Direct Obstetric Complications (MDOC) and related deaths in the 3 health zones (HZ) in the North-Kivu Province of Eastern Democratic Republic of Congo (DRC), 2016

\begin{tabular}{lll}
\hline MDOC diagnosed in the facilities surveyed & $\begin{array}{l}\text { Occurrences of MDOC by causes } \\
\mathbf{n}(\%)\end{array}$ & $\begin{array}{l}\text { Deaths related } \\
\text { to MDOC } \\
\mathbf{n}(\%)\end{array}$ \\
\hline Ante or postpartum haemorrhage & $261(47.9)$ & $14(50.0)$ \\
Retained placenta & $6(1.1)$ & $1(3.6)$ \\
Ruptured uterus & $56(10.3)$ & $4(14.3)$ \\
Postpartum sepsis & $82(15.0)$ & $4(14.3)$ \\
Severe pre-/eclampsia & $95(17.4)$ & $3(10.7)$ \\
Abortion complications & $40(7.3)$ & $1(3.6)$ \\
Ectopic pregnancy & $5(0.9)$ & $1(3.6)$ \\
Total & $545(100)$ & $28(100)$ \\
\hline
\end{tabular}

placed on further addressing residual insecurity in the 3 $\mathrm{HZs}$, which is paramount in reducing preventable mortality in conflict-affected populations [29].

Very few of the facilities surveyed performed all the 7 basic signal functions in the past 3 months, with AVD being the least frequently performed. This parallels the findings of a previous survey on the provision of key health services in a national sample of health facilities in DRC. It revealed that less than $12 \%$ of those offering maternity services were performing all basic EmONC services [46]. Also, the finding that AVD was the least likely signal function to be reported, especially in $\mathrm{HCs}$, is consistent with existing literature on the subject in SSA $[47,48]$.

If we were to ignore AVD, the $3 \mathrm{HZs}$ could meet the target of at least 5 functioning EmONC facilities for 500, 000 people. While most facilities couldn't offer this signal function on policy grounds (i.e., $\mathrm{HZ}$ or facility

Table 7 Availability of staff for emergency obstetric and newborn care (EmONC) services per level of facilities and per study health zones (HZ) in the North-Kivu Province of Eastern Democratic Republic of Congo (DRC), 2017

\begin{tabular}{|c|c|c|c|c|c|}
\hline \multirow[t]{2}{*}{ Health zones and facilities } & \multicolumn{5}{|c|}{ Staff for EmONC services } \\
\hline & $\overline{\text { All }}$ & Nurses & Midwives* & Medical doctors & \\
\hline \multirow[t]{2}{*}{ Overall } & 519 & 325 & $64^{a}$ & 130 & \\
\hline & & & & Specialists† & General practitioners \\
\hline $\operatorname{RF}(n=18)$ & 384 & $204\left(62.8^{\ddagger}\right)$ & 50 & 17 & 113 \\
\hline $\mathrm{HC}(\mathrm{n}=24)$ & 135 & $121\left(37.2^{\ddagger}\right)$ & 14 & NA & NA \\
\hline Median number per facility & _- & $6($ IQR 4-8) & $2(\mathrm{IQR} 1.5-4)$ & $3.5^{\ddagger}(\mathrm{IQR} 2-10)$ & \\
\hline Goma & 198 & 96 & $25^{b}$ & 77 & \\
\hline $\operatorname{RF}(n=6)$ & 163 & $63\left(65.6^{\ddagger}\right)$ & 23 & 16 & 61 \\
\hline$H C(n=5)$ & 35 & $33\left(34.4^{\ddagger}\right)$ & 2 & NA & NA \\
\hline Median number per facility & _- & 7 (IQR 6-12) & $4(\mathrm{IQR} 2-4)$ & $9.5^{\ddagger}(\mathrm{IQR} 8-13)$ & \\
\hline Karisimbi & 150 & 102 & $19^{c}$ & 29 & \\
\hline $\operatorname{RF}(n=6)$ & 105 & $63\left(61.8^{\ddagger}\right)$ & 13 & 0 & 29 \\
\hline $\mathrm{HC}(n=8)$ & 45 & $39\left(38.2^{\ddagger}\right)$ & 6 & NA & NA \\
\hline Median number per facility & - & 7 (IQR 5-9) & $2(\operatorname{QQR} 1-3)$ & $3^{\ddagger}(\mathrm{IQR} 2-8)$ & \\
\hline Rutshuru & 171 & 127 & $20^{d}$ & 24 & \\
\hline $\operatorname{RF}(n=6)$ & 116 & $78\left(61.4^{\ddagger}\right)$ & 14 & 1 & 23 \\
\hline $\mathrm{HC}(\mathrm{n}=11)$ & 55 & $49\left(38.6^{\ddagger}\right)$ & 6 & NA & NA \\
\hline Median number per facility & - & $4($ IQR 3-5) & $2(\mathrm{IQR} 1.5-3.5)$ & $2^{\ddagger}(\operatorname{IQR} 2-3)$ & \\
\hline
\end{tabular}

HC: health centres, RF: referral facilities (referral hospitals and referral health centres), IQR: interquartile range

${ }^{\ddagger}$ Percentages of nurses in the study health zones per level of facilities

${ }^{\ddagger}$ Obstetricians and paediatricians

*Not available in 18 facilities (4 HCs in Goma, 5HCs in Karisimbi, 2 RHCs and 7 HCs in Rutshuru)

${ }^{a} \operatorname{RF}(n=16), \operatorname{HC}(n=8),{ }^{b} \operatorname{RF}(n=6), \operatorname{HC}(n=1) 7,{ }^{c} \operatorname{RF}(n=6), \operatorname{HC}(n=3),{ }^{d} \operatorname{RF}(n=4) \operatorname{HC}(n=4)$

${ }^{\ddagger}$ In $\mathrm{RH}$ and $\mathrm{RHC}$ only

NA: not applicable, _: not calculated 
Table 8 Availability of essential drugs, equipment, ambulance and communication means in the facilities surveyed in the 3 health zones (HZs) in the North-Kivu Province of Eastern DRC, 2017

\begin{tabular}{|c|c|c|c|c|c|c|c|}
\hline \multirow{3}{*}{$\begin{array}{l}\text { Drugs, equipment and other } \\
\text { infrastructures }\end{array}$} & \multirow{3}{*}{ 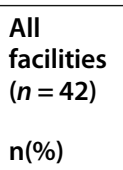 } & \multicolumn{2}{|l|}{ HZ of Goma } & \multicolumn{2}{|c|}{$\mathrm{HZ}$ of Karisimbi } & \multicolumn{2}{|c|}{ HZ of Rutshuru } \\
\hline & & $\begin{array}{l}\mathrm{RH} \text { and } \\
\mathrm{RHC}(n=6)\end{array}$ & $\begin{array}{l}\mathrm{HC} \\
(n=5)\end{array}$ & $\begin{array}{l}\text { RH and } \\
\mathrm{RHC}(\mathrm{n}=6)\end{array}$ & $\begin{array}{l}\mathrm{HC} \\
(\mathrm{n}=8)\end{array}$ & $\begin{array}{l}\mathrm{RH} \text { and } \\
\mathrm{HC}(n=6)\end{array}$ & $\begin{array}{l}\mathrm{HC} \\
(n=11)\end{array}$ \\
\hline & & $n(\%)$ & $n(\%)$ & n(\%) & $\mathrm{n}(\%)$ & $\mathrm{n}(\%)$ & $\mathrm{n}(\%)$ \\
\hline \multicolumn{8}{|l|}{ Drugs } \\
\hline Injectable beta-lactams & $42(100)$ & $6(100)$ & $5(100)$ & $6(100)$ & $8(100)$ & $6(100)$ & $11(100)$ \\
\hline Injectable metronidazole & $33(78.6)$ & $6(100)$ & $5(100)$ & $6(100)$ & $6(75.0)$ & $6(100)$ & $4(36.4)$ \\
\hline Magnesium sulphate & $19(45.2)$ & $6(100)$ & $3[43]$ & $6(100)$ & $2(25.0)$ & $5(83.3)$ & $0(0)$ \\
\hline Diazepam & $39(92.8)$ & $6(100)$ & $3(60.0)$ & $6(100)$ & $8(100)$ & $6(100)$ & $10(90.9)$ \\
\hline Anti-hypertensive drugs & $26(61.9)$ & $6(100)$ & $2(40.0)$ & $6(100)$ & $6(75.0)$ & $5(83.3)$ & $1(9.1)$ \\
\hline Oxytocics & $42(100)$ & $6(100)$ & $5(100)$ & $6(100)$ & $8(100)$ & $6(100)$ & $11(100)$ \\
\hline Crystalloid fluids & $42(100)$ & $6(100)$ & $5(100)$ & $6(100)$ & $8(100)$ & $6(100)$ & $11(100)$ \\
\hline \multicolumn{8}{|l|}{ Equipment } \\
\hline Foetal stethoscope & $42(100)$ & $6(100)$ & $5(100)$ & $6(100)$ & $8(100)$ & $6(100)$ & $11(100)$ \\
\hline Blood pressure cuff & $42(100)$ & $6(100)$ & $5(100)$ & $6(100)$ & $8(100)$ & $6(100)$ & $11(100)$ \\
\hline Filled oxygen cylinder & $12(28.9)$ & $6(100)$ & $0(0)$ & $3(50.0)$ & $0(0)$ & $3(50.0)$ & $0(0)$ \\
\hline Catheter for IV line & $40(95.2)$ & $6(100)$ & $5(100)$ & $6(100)$ & $7(87.5)$ & $6(100)$ & $10(90.9)$ \\
\hline Uristix & $26(61.9)$ & $3(50.0)$ & $2(40.0)$ & $6(100)$ & $5(62.5)$ & $6(100)$ & $4(36.4)$ \\
\hline Neonatal IV fluid set & $22(52.4)$ & $6(100)$ & $3(60.0)$ & $6(100)$ & $3(37.5)$ & $4(66.7)$ & $0(0)$ \\
\hline Neonatal bag and mask & $27(64.3)$ & $6(100)$ & $2(40.0)$ & $6(100)$ & $4(50.0)$ & $6(100)$ & $3(27.3)$ \\
\hline Kit for uterine evacuation & $28(66.7)$ & $4(66.7)$ & $4(80.0)$ & $5(83.3)$ & $4(50.0)$ & $6(100)$ & $5(45.5)$ \\
\hline Aspirator & $35(83.3)$ & $6(100)$ & $5(100)$ & $6(100)$ & $7(87.5)$ & $6(100)$ & $5(45.5)$ \\
\hline Vacuum extractor & $9(21.4)$ & $6(100)$ & $1(20.0)$ & $1(16.7)$ & $0(0)$ & $1(16.7)$ & $0(0)$ \\
\hline Resuscitation table & $35(83.3)$ & $6(100)$ & $4(80.0)$ & $6(100)$ & $8(100)$ & $6(100)$ & $5(45.5)$ \\
\hline \multicolumn{8}{|l|}{ Other infrastructures } \\
\hline Ambulancet & $10(23.8)$ & $3(50.0)$ & $0(0)$ & $3(50.0)$ & $0(0)$ & $4(66.7)$ & $0(0)$ \\
\hline Communication means for referralł & $16(38.1)$ & $6(100)$ & $0(0)$ & $6(1009$ & $0(0)$ & $3[44]$ & $1[9]$ \\
\hline
\end{tabular}

$\mathrm{RH}$ : referral hospital, $\mathrm{RHC}$ : referral health centre, HC: health centre, IV: intravenous tCar or motorcycle

$\neq$ Cell phone or two-way radio

policies not allowing the performance of a signal function), half of the facilities that reported 'no indication' didn't have a vacuum extractor for instrumental vaginal delivery. Restrictive policies targeted mainly HCs regardless of their location, illustrating a perceived lack of trained operators at that level of care. Moreover, $50 \%$ of facilities that owned a vacuum extractor did not indicate any AVD, which might reflect unfamiliarity with this technique. Lack of equipment and limited staff training and exposure are common obstacles to the performance of AVD in resource-poor settings [49-52]. Similarly, restrictive policies and the lack of equipment/drugs were the main reasons why neonatal resuscitation and parenteral administration of anticonvulsants could not be performed.

Restrictive policies raise concerns as to training and practice opportunities for health providers, especially those working in HCs. These restrictions, along with a lack of equipment, compromise chances for health providers to acquire skills and contribute to maintaining a situation where targeted services remain virtually unavailable at the primary health care level [50]. In line with WHO guidelines [53], interventions prioritising competency-based training for frontline providers and the use of simple and cost-effective equipment have been proved effective $[54,55]$. Such programming could offer a practical alternative to restrictive policies and promote better access to quality primary health care, which is a key step toward post-conflict health recovery $[43,56]$.

In Karisimbi and Rutshuru, none of the HCs administered anticonvulsants and, very few had stocked magnesium sulphate, the anticonvulsant of choice, shown to avert up to $85 \%$ of severe pre-/eclampsia (SPE) related deaths and disabilities [57]. This suggests that it was very likely for a pregnant woman presenting with SPE to be 
referred without being administered the loading dose of magnesium sulphate $(10 \mathrm{mg})$. In rural Bangladesh, Shamsuddin et al. found better maternal and perinatal prognoses in pregnant women who received the loading dose before referral than in those that did not [58].

Health facilities in Goma outperformed those in Karisimbi and Rutshuru in terms of service provision, overall. The performance of more EmONC signal functions in urban settings has already been reported in SSA [59] and in South-East Asia [60], a disparity that might illustrate an imbalance in the procurement of medical supplies and equipment, in training opportunities, and in the posting and retention of skilled health staff. Remarkably, two of the three functioning cEmONC facilities catered to the urban population, which might imply better access to comprehensive life-saving care for pregnant women in Goma. Of note, the presence of a functioning cEmONC facility in Rutshuru is consistent with a previous study in rural humanitarian settings in the North Kivu province of eastern DRC [61].

The inadequacies of the EmONC services found in state-run facilities in the study HZs are concordant with previous literature in DRC [61-63]. They appear to be systemic in nature and might reflect the level of public resource allocation for the health system. Available evidence points to this analysis. The DRC government expenditure on health (USD 12-13 per capita) is one the lowest in SSA [64], with a health budgetary allocation (4-5\%) far below the 2001 Abuja declaration target of at least $15 \%$ of the national budget to be allocated to the health sector to ensure universal care coverage $[65,66]$. Also, studies in DRC showed other factors related to persistent fragility that create bottlenecks in the functioning of the health system, including dependence on user fees and fragmented/vertical multi-donor inputs, inefficient budget preparation approaches, unmonitored budget execution, and poor governance [67-69]. Previously identified barriers to the delivery of EmONC in post-conflict SSA included systemic and human resource factors such as limited infrastructures and procurements, insignificant and erratic pay and poor living and working conditions of health workers [44].

Our results show that about half of facility births in the HZs of Goma and Karisimbi took place in referral NFPOs and that these facilities hired a higher proportion of health staff in both HZs and performed more signal functions. This tends to reflect how the availability of enough resources translates into adequate functionality of health facilities and points to women's self-referral behaviour to seek maternal care where better quality is perceived, as shown in previous work [70-72]. A study by Tabatabai $\mathrm{P}$ et al. in southern Tanzania comparing faith-based organisations (FBO) and public hospitals found that maternal health service capacity was more appropriate in FBOs [73]. In addition, the number of EmONC functions performed during a given time period has been shown to have an effect (i.e, for each additional EmONC SF available, bypassing odds decrease substanatially) on bypassing frontline facilities for childbirth care $[71,74]$. However, bypassing frontline facilities has an incidence on the number of cases of deliveries and pregnancy-related complications primary care health workers can see and manage in a given time period, perpetuating low EmONC functionality [75].

In the rural $\mathrm{HZ}$ of Rutshuru, the $\mathrm{RH}$ attended over a third of deliveries and four fifths of CS and hired the majority of health workers across the HZ. These findings reflect the impact of humanitarian assistance through financial and technical support that this $\mathrm{RH}$ was receiving from MSF. For example, in a rural conflict-affected district in Afghanistan, Lagrou D et al. found a steady increase in caseload at a cEmONC facility run by MSF [76]. In Rutshuru, MSF offered user fees exemption for $\mathrm{CS}$ and a maternity-waiting home, measures proven to address inequities in childbirth care [77, 78]. However, this assistance comes with potential downsides. First, by absorbing the majority of cases within a health district, humanitarian-assisted hospitals deprive other facilities, particularly primary care ones, of being exposed to case management, undermining the acquisition and maintenance of necessary skills. Also, it raises sustainability concerns, given the time-bound nature of its implementation [79].

The DOCFR exceeded the maximum acceptable level, suggesting poor quality of EmONC. Similar findings were reported in DRC and other SSA countries [50, 62, 63, 80-82]. However, given the observation that all direct obstetric deaths occurred only in the referral facilities, this indicator might also be reflective of the state of referral systems in the study HZs. Inadequate means of transportation and communication to link referring and receiving facilities may have contributed to the delayed arrival of unannounced referrals of women with MDOC at higher levels of EmONC, further compromising the prognosis. Maternal mortality audits in resourceconstrained settings have pointed to a number of barriers to timely access to EmONC, including inappropriate and ineffective referral, inefficient ambulance services, cost of transportation, and long waiting time before care is received at higher-level facilities [83, 84].

The population-based CS rate was the only process indicator found to be within an acceptable range in 2 of our study HZs. This is in contrast with findings from an EmONC study in Lubumbashi, the second largest city in DRC, barely affected by the 2006-2013 conflict episodes, that revealed an unmet need for CS deliveries [63]. These CS rates in the study HZs are rather encouraging, reflecting the contribution of humanitarian actors and 
NFPOs to the provision of public maternal and newborn health care services in the region. Even in the $\mathrm{HZ}$ of Karisimbi where none of the facilities qualified as functioning EmONC facility, the population-based CS rate was within the limits set by the WHO.

Since only a little over one-sixth of deliveries occurred in functioning EmONC and given the shortcomings in referral capabilities and unmet minimum acceptable levels of use and quality, one can surmise that most pregnancy-related complications had likely received substandard or delayed care. One systematic review found an inverse correlation between the met need for EmONC and maternal mortality ratio [85], highlighting the impact of better access to quality EmONC on reducing preventable mortality, a key element in postconflict recovery. A study in Nigeria identified factors contributing to maternal mortality, including a dysfunctional referral system and limited intensive care capabilities causing delays in providing EmONC [84].

This study has some limitations. First, only three out of the $34 \mathrm{HZs}$ in the North-Kivu Province were included in a purposive manner and, therefore, our findings and analyses cannot be generalized to the whole Province. The EmONC status in HZs located further to the 2006-2013 conflict events might be different. Second, profit-run health facilities were not selected, which very likely underestimated the provision and capacity of EmONC as well as facility deliveries in the $3 \mathrm{HZs}$. Our findings can also not be extrapolated to these facilities. Third, we did not assess staff knowledge of EmONC procedures and standards of care, leaving gaps in the actual ability to provide quality care in the study HZs and calling for further research. Fourth, we collected data in 2017 and this might raise concerns as to the current pertinence of our findings. Nevertheless, recent qualitative findings on health services for women, children, and adolescents in North Kivu, highlighting human resource and logistic barriers, might suggest that this study remains relevant [86].

\section{Conclusion}

This study gives for the first time a quantitative assessment of the post-conflict status of EmONC in the North-Kivu Province in eastern DRC. By identifying the gaps in the availability, use and quality of EmONC in the study HZs, it raises the prospect for evidence-based policies and programming, as well as coordinated EmONC interventions, which should encourage local and external stakeholders to work together in improving maternal and neonatal health in the province as part of the post-conflict recovery efforts. Despite the fact that most process/performance indicators didn't meet the WHO standards, EmONC services were provided to a degree that appeared to be more advantageous for urban populations and more comprehensive in public referral facilities, especially where the NFPO or humanitarian partners were involved. Special attention to basic EmONC and referral linkage among public health facilities is required, particularly in non-urban HZs, with an emphasis on strengthening human resources, equipment, supply chains, and referral capacity, on the one hand, and on tackling residual insecurity that might hinder $24 / 7$ staff availability, on the other hand. In view of the marked inadequacy between the number of $\mathrm{HCs}$ (designated bEmONC points) and the provision of basic signal functions across the study $\mathrm{HZs}$, initial efforts to improve access to quality EmONC could be directed towards upgrading the capacities of a few HCs (i.e., through supplying and equipping them appropriately, as well as through in-service training programmes), starting with those located in non-urban HZs. There is also the need to review the existing policies with respect to restrictions on the provision of EmONC signal functions in primary health care centres, particularly on AVD and neonatal resuscitation, provided appropriate planning and support. This study was conducted before the 2018 Ebola outbreak in North Kivu. The Ebola outbreak disrupted the provision of, and access to, essential health services, including EmONC [87]. Thus, our data can form a baseline for a follow-up survey to update and evaluate the status of EmONC service provision in these HZs.

\section{Abbreviations}

EmONC: emergency obstetric and newborn care; NKP: North Kivu Province; DRC: Democratic Republic of the Congo; HZ: Health zone; SSA: Sub-Saharan Africa; IAWG: The Inter-Agency Working Group for Reproductive Health; SRH: sexual and reproductive health; UN: United Nations; MRP: Manual removal of placenta; RRP: Removal of retained products of conception; AVD: Assisted vaginal delivery; NR: Neonatal resuscitation; CS: Caesarean section; CNDP: Congrès National pour la Défense du Peuple; M23: Mouvement du 23 Mars; CBHZ: Central Bureau of the Health Zone; HC: Health centre; RHC: Referral health centre; RH: Referral hospital; MOH: Minister of Health; AMDD: Averting Maternal Death and Disability; WHO: World Health Organization; UN: United Nations; UNICEF: United Nations' Children Fund; UNFPA: United Nations Population Funds; CMO: Chief Medical Officer; PI: Principal investigator; NFPO: non-for-profit organisations; MSF: Médecins Sans Frontières; USD: United States Dollars; MDOC: Major direct obstetric complications; DOCFR: Direct obstetric case facility rate; INMR: Intrapartum and very early neonatal death rate; IQR: Interquartile Range; SPE: Severe pre-/eclampsia

\footnotetext{
Acknowledgements

We sincerely acknowledge the $\mathrm{CBHZ}$ teams at every study $\mathrm{HZ}$ and the heads of each study facility; the former diligently authorized this study and provided relevant information on their health zones, while the latter welcomed the study team with an open and cooperative attitude. Special thanks to the data collection team-Adeline Chibampola, Merveille Isiya, Christophe Ahadi, and Grâce Mumbere-for their relentless efforts and positive attitudes throughout the collection phase. We also thank the Department of Global Health and Social Epidemiology at Kyoto University for their peer mentoring policies, which significantly helped shape this study through insightful contributions at various stages.
} 


\section{Authors' contributions}

SAM, KM, CW conceived of the study. SAM, KM, PMM, KOM, and CW contributed to study and survey design. SAM and GM contributed to pilot testing, study implementation and data collection. SAM, KM, CW and PMM contributed to data analysis; SAM, PMM, CW, KM and KOM contributed to data interpretation. SAM drafted the initial manuscript; all authors contributed to manuscript revision and have approved the final version.

\section{Funding}

This study was funded by the Kyoto University, Inter-graduate School program for sustainable development and survivable societies, which was sponsored by the Ministry of Education, Culture, Sports, Science and Technology (MEXT), Japan. The funders had no role in study design, data management (collection and analysis), the preparation of the manuscript or decision to publish.

\section{Availability of data and materials}

The minimal dataset necessary to interpret and build upon our findings is included in this article. Further dataset inquiry can be submitted to the corresponding author upon reasonable request.

\section{Declarations}

\section{Ethics approval and consent to participate}

This study was approved by Kyoto University Graduate School and Faculty of Medicine, Ethics Committee, Japan, as well as by the Ethics Committee of the University of Kinshasa School of Public Health, DRC. Written consent was obtained from all study interviewed participants before initiating data collection.

\section{Consent for publication}

Not applicable.

\section{Competing interests}

The authors declare that they have no competing interests.

\section{Author details}

${ }^{1}$ Graduate School of Medicine, School of Public Health, Department of Health Informatics, Kyoto University, Kyoto, Japan. ${ }^{2}$ African Population and Health Research Centre, Manga Close, P.O. Box 10787-00100, Nairobi, Kenya. ${ }^{3}$ Interdisciplinary Unit for Global Health, Centre for the Promotion of Interdisciplinary Education and Research, Kyoto University, Yoshida honmachi, Sakyo-ku, Kyoto 606-8501, Japan. ${ }^{4}$ International Institute of Socio-Epidemiology, Kitagosho-cho, Sakyo-ku, Kyoto 606-8336, Japan. ${ }^{5}$ Department of Paediatrics, University Hospital of Kinshasa, School of Medicine, Kinshasa, Democratic Republic of the Congo.

\section{Received: 4 December 2020 Accepted: 8 July 2021}

\section{Published online: 11 August 2021}

\section{References}

1. Paxton A, Maine D, Freedman L, Fry D, Lobis S. The evidence for emergency obstetric care. Int J Gynecol Obstet. 2005;88(2):181-93 https://doi.org/10.101 6/j.ijgo.2004.11.026.

2. Wall SN, Lee ACC, Carlo W, Goldenberg R, Niermeyer S, Darmstadt GL, et al. Reducing intrapartum-related neonatal deaths in low- and middle-income countries—what works? Semin Perinatol. 2010;34(6):395-407 https://doi. org/10.1053/j.semperi.2010.09.009.

3. Pattinson R, Kerber K, Buchmann E, Friberg IK, Belizan M, Lansky S, et al. Stillbirths: how can health systems deliver for mothers and babies? Lancet. 2011;377(9777):1610-23 https://doi.org/10.1016/S0140-6736(10)62306-9.

4. Lee AC, Cousens S, Darmstadt GL, Blencowe H, Pattinson R, Moran NF, et al. Care during labour and birth for the prevention of intrapartum-related neonatal deaths: a systematic review and Delphi estimation of mortality effect. BMC Public Health. 2011;1 1(3):S10 https://doi.org/10.1 186/1471-2458-11-S3-S10.

5. Bhandari TR, Dangal G. Emergency obstetric care: strategy for reducing maternal mortality in developing countries. Nepal J Obstet Gynaecol. 2014; 9(1):8-16 https://doi.org/10.3126/njog.v9i1.11179.

6. Alkema L, Chou D, Hogan D, Zhang S, Moller A-B, Gemmill A, et al. Global, regional, and national levels and trends in maternal mortality between 1990 and 2015, with scenario-based projections to 2030: a systematic analysis by the UN maternal mortality estimation inter-agency group. Lancet. 2016; 387(10017):462-74 https://doi.org/10.1016/S0140-6736(15)00838-7.

7. Hug L, Alexander M, You D, Alkema L. National, regional, and global levels and trends in neonatal mortality between 1990 and 2017, with scenariobased projections to 2030: a systematic analysis. Lancet Glob Health. 2019; 7(6):e710-20 https://doi.org/10.1016/S2214-109X(19)30163-9.

8. Williams PD. Continuity and change in war and conflict in Africa. PRISM. 2017:6(4):32-45.

9. Ghobarah HA, Huth P, Russett B. The post-war public health effects of civi conflict. Soc Sci Med. 2004;59(4):869-84 https://doi.org/10.1016/j. socscimed.2003.11.043.

10. O'Hare BAM, Southall DP. First do no harm: the impact of recent armed conflict on maternal and child health in sub-Saharan Africa. J R Soc Med. 2007;100(12):564-70 https://doi.org/10.1177/0141076807100012015.

11. d'Harcourt E, Purdin S. Impact of wars and conflict on maternal and child health. In: Ehiri J, editor. Maternal and child health: global challenges, programs, and policies. Boston: Springer US; 2009. p. 121-33. https://doi. org/10.1007/b106524_7.

12. Urdal $H$, Che CP. War and gender inequalities in health: the impact of armed conflict on fertility and maternal mortality. Int Interact. 2013;39(4): 489-510 https://doi.org/10.1080/03050629.2013.805133.

13. Wise PH, Darmstadt GL. Confronting stillbirths and newborn deaths in areas of conflict and political instability: a neglected global imperative. Paediatr Int Child Health. 2015;35(3):220-6 https://doi.org/10.1179/2046905515Y. 0000000027.

14. DeJong J, Ghattas H, Bashour H, Mourtada R, Akik C, Reese-Masterson A. Reproductive, maternal, neonatal and child health in conflict: a case study on Syria using countdown indicators. BMJ Glob Health. 2017;2(3):e000302 https://doi.org/10.1136/bmjgh-2017-000302.

15. Wagner Z, Heft-Neal S, Bhutta ZA, Black RE, Burke M, Bendavid E. Armed conflict and child mortality in Africa: a geospatial analysis. Lancet Lond Engl. 2018:392(10150):857-65.

16. OECD. States of fragility 2015: meeting Post-2015 ambitions. Paris: OECD Publishing; 2015. https://doi.org/10.1787/9789264227699-en

17. Boerma T, Requejo J, Victora CG, Amouzou A, George A, Agyepong I, et al. Countdown to 2030: tracking progress towards universal coverage for reproductive, maternal, newborn, and child health. Lancet. 2018;391(10129): 1538-48 https://doi.org/10.1016/50140-6736(18)30104-1.

18. Ameh CA, Mdegela M, White $S$, van den Broek $N$. The effectiveness of training in emergency obstetric care: a systematic literature review. Health Policy Plan. 2019;34(4):257-70 https://doi.org/10.1093/heapol/czz028.

19. Say L, Chou D, Gemmill A, Tunçalp Ö, Moller A-B, Daniels J, et al. Global causes of maternal death: a WHO systematic analysis. Lancet Glob Health. 2014;2(6):e323-33 https://doi.org/10.1016/S2214-109X(14)70227-X.

20. Ahmed I, Ali SM, Amenga-Etego S, Ariff S, Bahl R, Baqui AH, et al. Population-based rates, timing, and causes of maternal deaths, stillbirths, and neonatal deaths in South Asia and sub-Saharan Africa: a multi-country prospective cohort study. Lancet Glob Health. 2018;6(12):e1297-308 https:// doi.org/10.1016/S2214-109X(18)30385-1.

21. Ronsmans C, Graham WJ. Maternal mortality: who, when, where, and why. Lancet. 2006;368(9542):1189-200 https://doi.org/10.1016/S0140-673 6(06)69380-X

22. World Health Organization. Trends in maternal mortality: 1990-2015: estimates from WHO, UNICEF, UNFPA, World Bank Group and the United Nations Population Division: World Health Organization; 2015.

23. Boerma T, Tappis H, Saad-Haddad G, Das J, Melesse DY, DeJong J, et al. Armed conflicts and national trends in reproductive, maternal, newborn and child health in sub-Saharan Africa: what can national health surveys tell us? BMJ Glob Health. 2019;4(Suppl 4):e001300 https://doi.org/10.1136/ bmjgh-2018-001300.

24. Foster AM, Evans DP, Garcia M, Knaster S, Krause S, McGinn T, et al. The 2018 inter-agency field manual on reproductive health in humanitarian settings: revising the global standards. Reprod Health Matters. 2017;25(51): 18-24 https://doi.org/10.1080/09688080.2017.1403277.

25. Tran N-T, Dawson A, Meyers J, Krause S, Hickling C. Inter-agency working group (IAWG) on reproductive health in crisis (2015) developing institutional capacity for reproductive health in humanitarian settings: a descriptive study. PLoS One. 2015;10(9):e0137412 https://doi.org/10.1371/ journal.pone.0137412.

26. Bailey P, Lobis S, Maine D, Fortney JA. Monitoring emergency obstetric care: a handbook. Geneva: World Health Organization; 2009. 
27. Pettersson T, Öberg M. Organized violence, 1989-2019. J Peace Res. 2020; 57(4):597-613 https://doi.org/10.1177/0022343320934986.

28. Coghlan B, Brennan RJ, Ngoy P, Dofara D, Otto B, Clements M, et al. Mortality in the Democratic Republic of Congo: a nationwide survey. Lancet Lond Engl. 2006;367(9504):44-51 https://doi.org/10.1016/S0140-673 6(06)67923-3.

29. Coghlan B, Ngoy P, Mulumba F, Hardy C, Bemo VN, Stewart T, et al. Update on mortality in the Democratic Republic of Congo: results from a third nationwide survey. Disaster Med Public Health Prep. 2009;3(2):88-96 https:// doi.org/10.1097/DMP.0b013e3181a6e952.

30. Save the Children, State of the World's Mothers 2014: Saving Mothers and Children in Humanitarian Crises, 2014, ISBN 1-888393-28-9. Available at: https://www.refworld.org/docid/53d60c3f4.html. Accessed 3 Nov 2017.

31. Wagner Z, Heft-Neal S, Wise PH, Black RE, Burke M, Boerma T, et al. Women and children living in areas of armed conflict in Africa: a geospatial analysis of mortality and orphanhood. Lancet Glob Health. 2019;7(12):e1622-31 https://doi.org/10.1016/52214-109X(19)30407-3.

32. Cometto G, Fritsche G, Sondorp E. Health sector recovery in early postconflict environments: experience from southern Sudan. Disasters. 2010; 34(4):885-909 https://doi.org/10.1111/j.1467-7717.2010.01174.x.

33. Bertone MP, Witter $S$. An exploration of the political economy dynamics shaping health worker incentives in three districts in Sierra Leone. Soc Sci Med. 2015;141:56-63 https://doi.org/10.1016/j.socscimed.2015.07.028.

34. Ssengooba F, Kawooya V, Namakula J, Fustukian S. Application of social network analysis in the assessment of organization infrastructure for service delivery: a three district case study from post-conflict northern Uganda. Health Policy Plan. 2017;32(8):1193-202 https://doi.org/10.1093/heapol/ c $2 \times 071$.

35. Bwimana A. Heath sector network governance and state-building in South Kivu, Democratic Republic of Congo. Health Policy Plan. 2017;32(10):147683 https://doi.org/10.1093/heapol/czX095.

36. Pavignani $\mathrm{E}$, Colombo $\mathrm{S}$. Analysing disrupted health sectors: a modular manual: World Health Organization; 2000. https://apps.who.int/iris/handle/1 0665/44299. Accessed 13 Dec 2018

37. Martineau T, McPake B, Theobald S, Raven J, Ensor T, Fustukian S, et al. Leaving no one behind: lessons on rebuilding health systems in conflictand crisis-affected states. BMJ Glob Health. 2017;2(2).

38. Ministère de la Santé Publique de la RDC. Plan National de Développement Sanitaire (PNDS 2011-2015). Kinshasa: 2010. [cited 2018 Mar 1]. Available from: https://www.who.int/hac/techguidance/training/analysing_health_ systems/5_normes_de_la_zone_de_sante_06.pdf.

39. Sundberg R, Melander E. Introducing the UCDP georeferenced event dataset. J Peace Res. 2013;50(4):523-32 https://doi.org/10.1177/00223433134 84347.

40. Ministère du Plan et Suivi de la Mise en œuvre de la Révolution de la Modernité - MPSMRM/Congo, Ministère de la Santé Publique - MSP/Congo and ICF International. Enquête Démographique et de Santé en République Démocratique du Congo 2013-2014. Rockville: MPSMRM, MSP, and ICF International; 2014

41. Krause SK, Meyers JL, Friedlander E. Improving the availability of emergency obstetric care in conflict-affected settings. Glob Public Health. 2006;1 (3):20528 https://doi.org/10.1080/17441690600679939.

42. Elfversson $\mathrm{E}$, Gusic I, Höglund K. The spatiality of violence in post-war cities. Third World Themat TWQ J. 2019;4(2-3):81-93 https://doi.org/10.1080/23802 014.2019.1675533.

43. Chi PC, Bulage P, Urdal H, Sundby J. Barriers in the delivery of emergency obstetric and neonatal care in post-conflict Africa: qualitative case studies of Burundi and northern Uganda. PLoS One. 2015;10(9):e0139120 https://doi. org/10.1371/journal.pone.0139120.

44. Chi PC, Bulage P, Urdal H, Sundby J. A qualitative study exploring the determinants of maternal health service uptake in post-conflict Burundi and northern Uganda. BMC Pregnancy Childbirth. 2015;15(1):18 https://doi.org/1 0.1186/s12884-015-0449-8.

45. Mugo N, Zwi AB, Botfield JR, Steiner C. Maternal and child health in South Sudan: priorities for the Post-2015 agenda. SAGE Open. 2015;5(2): 2158244015581190.

46. Ministère de la Santé Publique [internet]. Enquête sur la Disponibilité et la capacité opérationnelle des services de santé en République Démocratique du Congo. Kinshasa: DSSP/DSNIS; 2014. [cited 2018 Mar 8]. Available from: https://apps.who.int/healthinfo/systems/datacatalog/index.php/catalog/54
47. Bailey P, Paxton A, Lobis S, Fry D. The availability of life-saving obstetric services in developing countries: an in-depth look at the signal functions for emergency obstetric care. Int J Gynecol Obstet. 2006;93(3):285-91 https:// doi.org/10.1016/j.ijgo.2006.01.028.

48. Wilunda C, Putoto G, Riva DD, Manenti F, Atzori A, Calia F, et al. Assessing coverage, equity and quality gaps in maternal and neonatal Care in subSaharan Africa: an integrated approach. PLoS One. 2015;10(5):e0127827 https://doi.org/10.1371/journal.pone.0127827.

49. Fauveau V. Is vacuum extraction still known, taught and practiced? A worldwide KAP survey. Int J Gynecol Obstet. 2006;94(2):185-9 https://doi. org/10.1016/j.jigo.2006.01.033.

50. Kongnyuy EJ, Leigh B, van den Broek N. Effect of audit and feedback on the availability, utilisation and quality of emergency obstetric care in three districts in Malawi. Women Birth. 2008;21(4):149-55 https://doi.org/10.1016/j. wombi.2008.08.002.

51. Ameh CA, Weeks AD. The role of instrumental vaginal delivery in low resource settings. BJOG Int J Obstet Gynaecol. 2009;116(s1):22-5 https://doi. org/10.1111/j.1471-0528.2009.02331.x.

52. Bailey PE, van Roosmalen J, Mola G, Evans C, de Bernis L, Dao B. Assisted vaginal delivery in low and middle income countries: an overview. BJOG Int J Obstet Gynaecol. 2017;124(9):1335-44 https://doi.org/10.1111/1471-052 8.14477.

53. World Health Organization, International Confederation of Midwives and Fédération internationale de Gynécologie et d'Obstétrique. Making pregnancy safer: the critical role of the skilled attendant : a joint statement by WHO, ICM and FIGO. Geneva: WHO; 2014. [cited 2018 July 26]. Available from: https://apps.who.int/iris/handle/10665/42955

54. Ameh CA, van den Broek N. Making it happen: training health-care providers in emergency obstetric and newborn care. Best Pract Res Clin Obstet Gynaecol. 2015;29(8):1077-91 https://doi.org/10.1016/.jbpobgyn.2015. 03.019.

55. Otolorin E, Gomez P, Currie S, Thapa K, Dao B. Essential basic and emergency obstetric and newborn care: from education and training to service delivery and quality of care. Int J Gynecol Obstet. 2015;130:S46-53 https://doi.org/10.1016/j.jpgo.2015.03.007.

56. Kruk ME, Rockers PC, Williams EH, Varpilah ST, Macauley R, Saydee G, et al. Availability of essential health services in post-conflict Liberia. Bull World Health Organ. 2010;88(7):527-34 https://doi.org/10.2471/BLT.09.071068.

57. Ronsmans C, Campbell O. Quantifying the fall in mortality associated with interventions related to hypertensive diseases of pregnancy. BMC Public Health. 2011;11(3):S8 https://doi.org/10.1186/1471-2458-11-S3-S8.

58. Shamsuddin L, Nahar K, Nasrin B, Nahar S, Tamanna S, Kabir RMA, et al. Use of parenteral magnesium sulphate in eclampsia and severe pre-eclampsia cases in a rural set up of Bangladesh. Bangladesh Med Res Counc Bull. 2005; 31(2):75-82.

59. Phiri SN, Fylkesnes K, Moland KM, Byskov J, Kiserud T. Rural-urban inequity in unmet obstetric needs and functionality of emergency obstetric Care Services in a Zambian District. PLoS One. 2016;1 1(1):e0145196 https://doi. org/10.1371/journal.pone.0145196.

60. Wichaidit W, Alam M-U, Halder AK, Unicomb L, Hamer DH, Ram PK. Availability and quality of emergency obstetric and newborn Care in Bangladesh. Am J Trop Med Hyg. 2016;95(2):298-306 https://doi.org/10.42 69/ajtmh.15-0350

61. Casey SE, Chynoweth SK, Cornier N, Gallagher MC, Wheeler EE. Progress and gaps in reproductive health services in three humanitarian settings: mixedmethods case studies. Confl Heal. 2015;9(1):S3 https://doi.org/10.1186/1 752-1505-9-S1-S3.

62. Casey SE, Mitchell KT, Amisi IM, Haliza MM, Aveledi B, Kalenga P, et al. Use of facility assessment data to improve reproductive health service delivery in the Democratic Republic of the Congo. Confl Heal. 2009:3(1):12 https:// doi.org/10.1186/1752-1505-3-12.

63. Ntambue AM, Malonga FK, Cowgill KD, Dramaix-Wilmet M, Donnen P. Emergency obstetric and neonatal care availability, use, and quality: a crosssectional study in the city of Lubumbashi, Democratic Republic of the Congo, 2011. BMC Pregnancy Childbirth. 2017;17(1):40 https://doi.org/10.11 86/s12884-017-1224-9.

64. Musango L, Elovainio R, Nabyonga Orem J, Toure B. HealtH monitor the Contents: Health Monit: 2013.

65. World Health Organization. Improving health system efficiency: Democratic Republic of the Congo: improving aid coordination in the health sector. 
Geneva: WHO; 2015. [cited 2018 Oct 26]. Available from: https://apps.who. int/iris/handle/10665/186673

66. Adebisi YA, Umah JO, Olaoye OC, Alaran AJ, Sina-Odunsi AB. Assessment of Health Budgetary Allocation and Expenditure Toward Achieving Universal Health Coverage in Nigeria. Int J Health Life Sci. 2020;6:2.

67. Le Gargasson J-B, Mibulumukini B, Gessner BD, Colombini A. Budget process bottlenecks for immunization financing in the Democratic Republic of the Congo (DRC). Vaccine. 2014;32(9):1036-42 https://doi.org/10.1016/j.vaccine.2 013.12.036.

68. Barroy H, André F, SMN M, Samaha HN. Investing in universal health coverage : opportunities and challenges for health financing in the Democratic Republic of Congo. Washington, D.C: World Bank Group; 2014 [cited 2019 May 19]. Available from http://documents.worldbank.org/cura ted/en/782781468196751651/Investing-in-universal-health-coverageopportunities-and-challenges-for-health-financing-in-the-DemocraticRepublic-of-Congo

69. Laokri S, Soelaeman R, Hotchkiss DR. Assessing out-of-pocket expenditures for primary health care: how responsive is the Democratic Republic of Congo health system to providing financial risk protection? BMC Health Serv Res. 2018;18(1):451 https://doi.org/10.1186/s12913-018-3211-x.

70. Tappis H, Koblinsky M, Doocy S, Warren N, Peters DH. Bypassing primary care facilities for childbirth: findings from a multilevel analysis of skilled birth attendance determinants in Afghanistan. J Midwifery Womens Health. 2016; 61(2):185-95 https://doi.org/10.1111/jmwh.12359.

71. Salazar M, Vora K, Costa AD. Bypassing health facilities for childbirth: a multilevel study in three districts of Gujarat, India. Glob Health Action. 2016; 9(1):32178 https://doi.org/10.3402/gha.v9.32178.

72. Mubiri P, Kajjo D, Okuga M, Marchant T, Peterson S, Waiswa P, et al. Bypassing or successful referral? A population-based study of reasons why women travel far for childbirth in eastern Uganda. BMC Pregnancy Childbirth. 2020;20(1):497 https://doi.org/10.1186/s12884-020-03194-2.

73. Tabatabai $P$, Henke S, Sušac K, Kisanga OME, Baumgarten I, Kynast-Wolf G, et al. Public and private maternal health service capacity and patient flows in southern Tanzania: using a geographic information system to link hospital and national census data. Glob Health Action. 2014;7(1):22883 https://doi.org/10.3402/gha.v7.22883.

74. Kanté AM, Exavery A, Phillips JF, Jackson EF. Why women bypass front-line health facility services in pursuit of obstetric care provided elsewhere: a case study in three rural districts of Tanzania. Tropical Med Int Health. 2016; 21(4):504-14 https://doi.org/10.1111/tmi.12672.

75. Allen SM, Opondo C, Campbell OMR. Measuring facility capability to provide routine and emergency childbirth care to mothers and newborns: an appeal to adjust for delivery caseload of facilities. PLoS One. 2017;12(10): e0186515 https://doi.org/10.1371/journal.pone.0186515.

76. Lagrou D, Zachariah R, Bissell K, Van Overloop C, Nasim M, Wagma HN, et al. Provision of emergency obstetric care at secondary level in a conflict setting in a rural area of Afghanistan - is the hospital fulfilling its role? Confl Heal. 2018;12(1):2 https://doi.org/10.1186/s13031-018-0137-1.

77. Fogliati P, Straneo M, Mangi S, Azzimonti G, Kisika F, Putoto G. A new use for an old tool: maternity waiting homes to improve equity in rural childbirth care. Results from a cross-sectional hospital and community survey in Tanzania. Health Policy Plan. 2017;32(10):1354-60 https://doi.org/1 0.1093/heapol/czx100.

78. Ravit M, Audibert M, Ridde V, De Loenzien M, Schantz C, Dumont A. Removing user fees to improve access to caesarean delivery: a quasiexperimental evaluation in western Africa. BMJ Glob Health. 2018;3(1).

79. Maini R, Lohmann J, Hotchkiss DR, Mounier-Jack S, Borghi J. What happens when donors pull out? Examining differences in motivation between health workers who recently had performance-based financing (PBF) withdrawn. with workers who never received PBF in the Democratic Republic of Congo. Int J Health Policy Manag. 2019;8(11):646-61 https://doi.org/10.15171/ ijhpm.2019.55.

80. Pearson L, Shoo R. Availability and use of emergency obstetric services: Kenya, Rwanda, Southern Sudan, and Uganda. Int J Gynecol Obstet. 2005; 88(2):208-15 https://doi.org/10.1016/j.jpgo.2004.09.027.

81. Admasu K. Haile- Mariam A, Bailey P. Indicators for availability, utilization, and quality of emergency obstetric care in Ethiopia, 2008. Int J Gynecol Obstet. 2011;115(1):101-5 https://doi.org/10.1016/j.jigo.2011.07.010.

82. Wilunda C, Oyerinde K, Putoto G, Lochoro P, Dall'Oglio G, Manenti F, et al. Availability, utilization and quality of maternal and neonatal health care services in Karamoja region, Uganda: a health facility-based survey. Reprod Health. 2015;12(1):30 https://doi.org/10.1186/s12978-015-0018-7.

83. Mgawadere F, Unkels R, Kazembe A, van den Broek N. Factors associated with maternal mortality in Malawi: application of the three delays model. BMC Pregnancy Childbirth. 2017;17(1):219 https://doi.org/10.1186/s12884-01 7-1406-5.

84. Hussein J, Hirose A, Owolabi O, Imamura M, Kanguru L, Okonofua F. Maternal death and obstetric care audits in Nigeria: a systematic review of barriers and enabling factors in the provision of emergency care. Reprod Health. 2016;13:1-11.

85. Holmer H, Oyerinde K, Meara JG, Gillies R, Liljestrand J, Hagander L. The global met need for emergency obstetric care: a systematic review. BJOG Int J Obstet Gynaecol. 2015;122(2):183-9 https://doi.org/10.1111/1471-052 8.13230 .

86. Altare C, Malembaka EB, Tosha M, Hook C, Ba H, Bikoro SM, et al. Health services for women, children and adolescents in conflict affected settings: experience from North and South Kivu, Democratic Republic of Congo. Confl Heal. 2020;14(1):31.

87. McKay G, Black B, Mbambu Kahamba S, Wheeler E, Mearns S, Janvrin A. Not all that bleeds is Ebola: how has the DRC Ebola outbreak impacted sexual and reproductive health in north-Kivu. New York: The International Rescue Committee; 2019

\section{Publisher's Note}

Springer Nature remains neutral with regard to jurisdictional claims in published maps and institutional affiliations.
Ready to submit your research? Choose BMC and benefit from:

- fast, convenient online submission

- thorough peer review by experienced researchers in your field

- rapid publication on acceptance

- support for research data, including large and complex data types

- gold Open Access which fosters wider collaboration and increased citations

- maximum visibility for your research: over $100 \mathrm{M}$ website views per year

At BMC, research is always in progress.

Learn more biomedcentral.com/submissions 